\title{
Bandaromimus Linnavuori (Homoptera, Cicadellidae, Deltocephalinae): primeiro registro no Brasil e descrição de duas espécies novas ${ }^{1}$
}

\author{
Keti Maria Rocha Zanol ${ }^{2}$
}

\begin{abstract}
Bandaromimus Linnavuori (Homoptera, Cicadellidae, Deltocephalinae): first record for Brazil and description of two new species. Bandaromimus Linnavuori, 1959 is reported for the first time in Brazil. Two new species are described: Bandaromimus matogrossensis sp. nov. (Brazil, Mato Grosso) and Bandaromimus insularis sp. nov. (Brazil, Paraná). The female of Bandaromimus parvicauda Linnavuori \& Heller, 1961 is described and the illustrations of male genitalia is also added. KEY WORDS. Homoptera, Cicadellidae, Deltocephalinae, Bandaromimus, taxonomy
\end{abstract}

LINNAVUORI (1959) descreveu Bandaromimus designando como espécietipo B. fulvopictus, do Peru e descreveu, também, B. australis da Argentina. LINNAVUORI \& HELLER (1961) descreveram Bandaromimus parvicauda do Peru.

As espécies de Bandaromimus caracterizam-se por apresentar a coroa de comprimento uniforme, região frontal microesculturada, região discal lisa, sutura coronal atingindo a metade do comprimento da coroa e ocelos, na margem anterior, visíveis de cima. Anteclípeo com ápice mais largo. Genas com leve reentrância abaixo dos olhos. Tégminas transparentes com duas células anteapicais fechadas; apêndice desenvolvido. Espinulação das tíbias anteriores 1+4 e dos fêmures posteriores $2+2+1$. Valva genital triangular. Placas subgenitais triangulares, com longos e numerosos pêlos, na superfície dorsal; macrocerdas unisseriadas, saindo longe da margem. Estilos digitiformes. Conetivo com os braços próximos. Edeago simétrico; gonóporo apical.

O material pertence à Coleção de Entomologia Pe J.S. Moure, Departamento de Zoologia, Universidade Federal do Paraná, Curitiba, Brasil (DZUP).

\section{Bandaromimus parvicauda Linnavuori \& Heller, 1961}

Figs 1-8

Bandaromimus parvicauda Linnavuori \& Heller, 1961: 12-13.

Fêmea. Cabeça com a coroa de cor marfim; margem anterior com seis manchas, arredondadas, marrons; região discal com uma mancha, transversa, fulva. Face amarela. Frontoclípeo com arcos laterais fulvos. Anteclípeo com uma mancha apical, fulva. Lora margeadas de marrom. Genas com uma mancha marrom, que se estende desde a lora até os olhos.

1) Contribuição número 1332 do Departamento de Zoologia, Universidade Federal do Paraná.

2) Departamento de Zoologia, Universidade Federal do Paraná. Caixa Postal 19020, 81531-980 Curitiba, Paraná, Brasil. Bolsista do CNPq. 

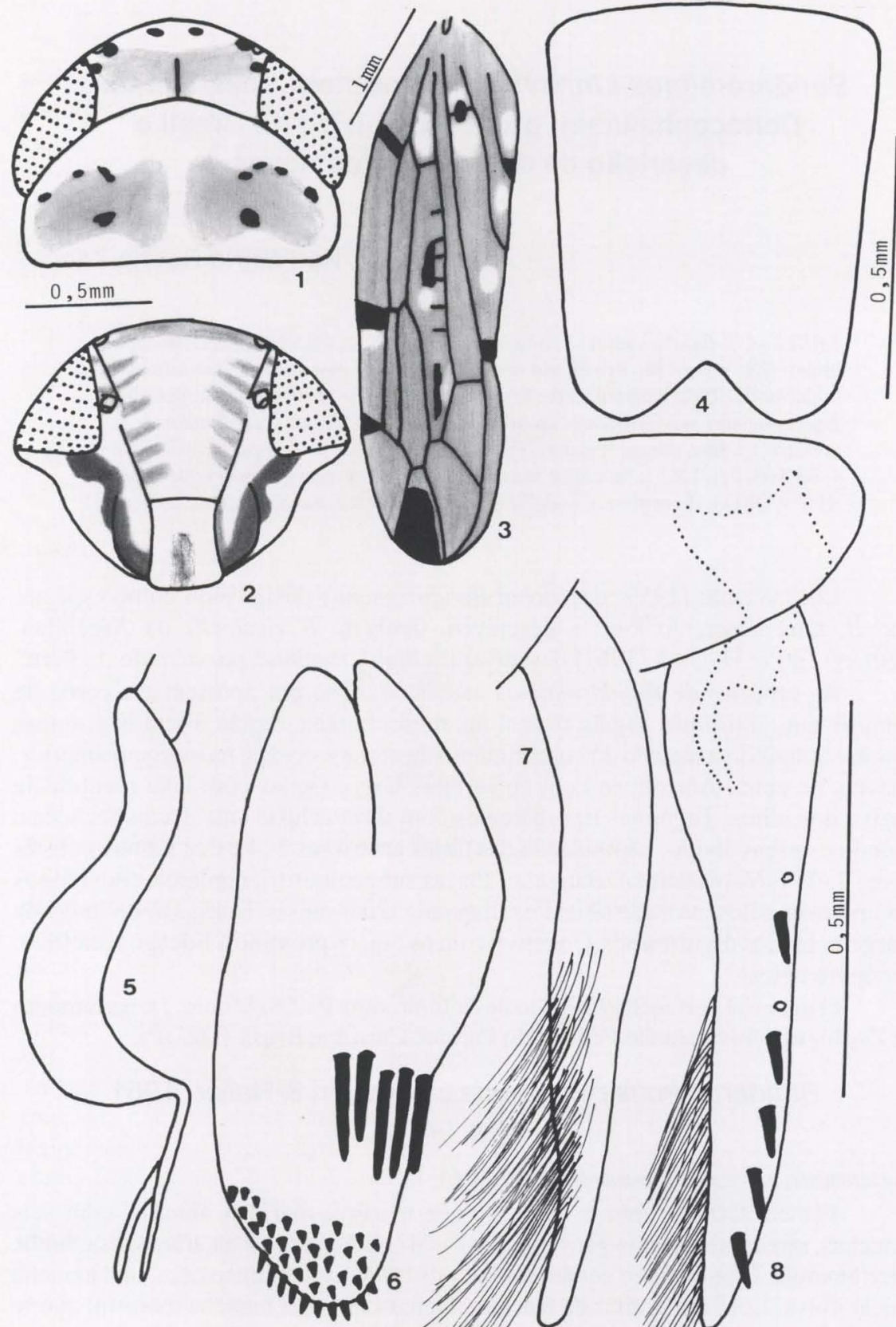

Figs 1-8. Bandaromimus parvicauda. (1-4) Fêmea: (1) cabeça e pronoto, (2) face, (3) tégmina, (4) sétimo esternito; (5-8) macho: (5) edeago, lateral, (6) pigóforo, lateral, (7) placa subgenital, dorsal, (8) valva, placa subgenital e estilo. 


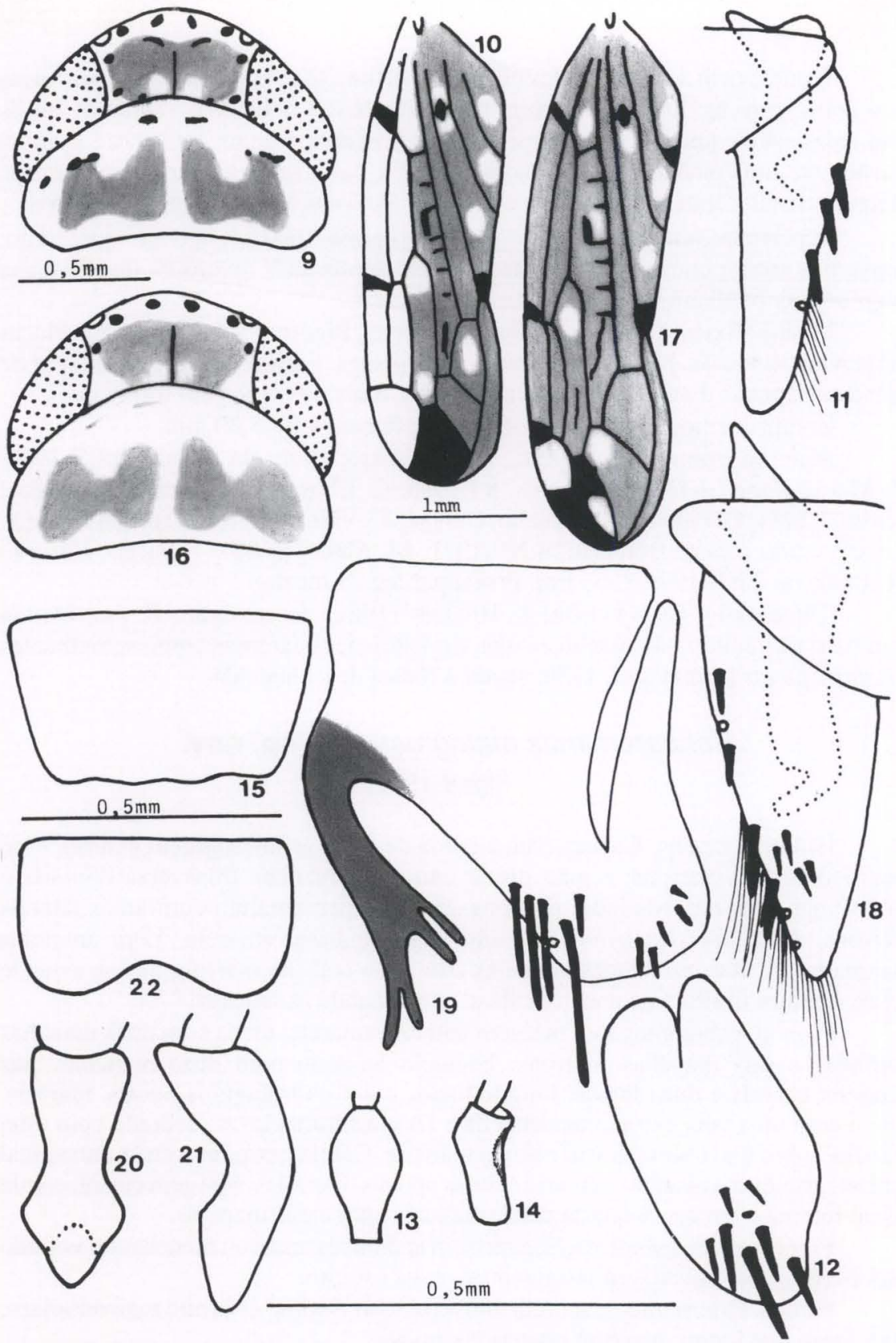

Figs 9-22. (9-15) Bandaromimus matogrossensis sp. nov., holótipo: (9) cabeça e pronoto, (10) tégmina, (11) valva, placa subgenital e estilo, (12) pigóforo, lateral, (13) edeago, ventral, (14) edeago, lateral, (15) parátipo: sétimo esternito, fêmea; (16-22) Bandaromimus insularis sp. nov., holótipo: (16) cabeça e pronoto, (17) tégmina, (18) valva, placa subgenital e estilo, (19) pigóforo, lateral, (20) edeago, ventral, (21) edeago, lateral, (22) parátipo: sétimo esternito da fêmea. 
Pronoto com as margens de coloração marfim; disco com duas manchas fulvas com áreas marrons. Escutelo marfim; triângulos basais dourados. Tégminas fulvas com áreas esbranquiçadas. Clavo com uma veia extranumerária entre $1 \mathrm{~A}$ e a sutura claval; com uma mancha sobre a extranumerária, outra junto à $2 \mathrm{~A}$ e ápice marrom. Margem costal, célula discal interna e terceira célula apical, com manchas marrons.

Superfície ventral amarela. Sétimo esternito mais longo do que largo; margem posterior com uma fenda mediana, em forma de $\mathrm{V}$ invertido; uma mancha longitudinal. mediana, marrom.

Macho. Externamente semelhante a fêmea. Pigóforo sem apêndices. Placas subgenitais sinuosas, longas com ápices divergentes. Edeago curvo com um par de apêndices apicais divergentes; em vista lateral, mais ou menos em forma de $S$.

Comprimento. Macho: 4,60-4,90 mm, fêmea: 4,80-5,00 mm.

Material examinado. Brasil, Mato Grosso: Barra do Bugres, 14.V.1980, M. Marques leg., 1 fêmea; Cáceres, 8.I.1985, C. Elias leg., 4 machos, 4 fêmeas; Coxim, I.1971, G. Allen leg., 1 macho; Cuiabá, 23.VIII.1971, Menezes e Allen leg., 1 macho. São Paulo: Botucatu, 4.XII.1971, M. Menezes leg., 1 macho. Paraná: Guarapuava, 2.XII.1996, Lev. Ent. Profaupar leg., 1 macho.

Comentário. LINNAVUORI \& HELLER (1961) descreveram B. parvicauda com base na genitália do macho e cujas características externas como semelhantes à B. fulvopictus Linnavuori, 1959, sendo a fêmea desconhecida.

\section{Bandaromimus matogrossensis sp. nov.}

Figs $9-15$

Holótipo macho. Cabeça com a coroa de cor marfim; margem anterior com quatro manchas marrons; região discal com uma mancha transversa dourada e quatro manchas, de cada lado, marrons. Frontoclípeo amarelo com arcos laterais marrons. Anteclípeo marrom com uma mancha basal amarela. Lora amarelas margeadas de marrom. Genas amarelas com uma mancha marrom que se estende desde a sutura frontoclipeal até os olhos, contornando as antenas.

Pronoto esbranquiçado; margem anterior amarela; disco com duas manchas douradas e seis manchas marrons. Escutelo amarelo com duas manchas, nas margens laterais e duas faixas, longitudinais, entre os triângulos basais, marfins. Clavo com uma veia extranumerária entre $1 \mathrm{~A}$ e a sutura claval; dourado com uma mancha sobre a extranumerária e ápice marrom. Célula braquial, célula anteapical central, primeira, segunda e terceira células apicais douradas. Margem costal, célula discal interna e terceira e quarta células apicais com áreas marrons.

Pigóforo sem apêndices. Edeago sem apêndices, mais ou menos reto, voltado para frente; terço apical, em vista ventral, mais estreito.

Fêmea. Externamente semelhante ao macho. Sétimo esternito marrom-claro, mais largo que longo; margem posterior sinuosa.

Comprimento. Macho: 4,20 mm, fêmea: 4,60 mm.

Material examinado. Holótipo macho do BRAsIL, Mato Grosso: Sinop, 13.XII.1986, M. Alvarenga leg. Parátipos. 1 macho e 5 fêmeas com os mesmos dados do holótipo (DZUP). 


\section{Bandaromimus insularis sp. nov.}

Figs 16-22

Holótipo macho. Cabeça com a coroa marfim; margem anterior com quatro manchas marrons; região discal com uma mancha, transversa, fulva e duas manchas, arredondadas, próximas aos olhos, marrons. Frontoclípeo marrom com uma faixa transversa, entre os ocelos, uma mancha longitudinal, de contorno irregular e arcos laterais amarelos. Anteclípeo marrom com uma mancha basal amarela Lora marrons com uma mancha amarela. Genas amarelas com uma mancha marrom, entre a sutura frontoclipeal e os olhos.

Pronoto marfim com duas manchas douradas; margem anterior com nuanças douradas. Escutelo marfim; triângulos basais amarelos. Tégminas douradas com áreas esbranquiçadas. Clavo com uma veia extranumerária entre $1 \mathrm{~A}$ e a sutura claval; uma mancha sobre a extranumerária, outra junto à $2 \mathrm{~A}$ e ápice marrons. Margem costal, célula discal interna, célula anteapical central e terceira célula apical com áreas marrons.

Pigóforo com um par de apêndices dorsais, curvos para baixo com os ápices recortados. Edeago sem apêndice, levemente curvo; próximo ao ápice, em vista ventral, expandido lateralmente como uma aba.

Fêmea. Externamente semelhante ao macho. Sétimo esternito marrom-claro, mais largo do que longo; margem posterior côncava.

Comprimento. Macho: 4,80 mm, fêmea: 4,60 mm.

Material examinado. Holótipo macho do BRASIL, Paraná: Paranaguá (Ilha do Mel, Fortaleza), 2.X.1988, R. Dutra leg. Parátipos. 1 macho e 3 fêmeas com os mesmos dados do holótipo (DZUP).

\section{REFERÊNCIAS BIBLIOGRÁFICAS}

LinNAvuori, R. 1959. Revision of the neotropical Deltocephalinae and some related subfamilies. Ann.

Zool. Soc. Bot. Fennicae Vanamo 20 (1): 1-370

LiNNAVUORI, R. \& F. HELLER. 1961. Beitrag zur cicadelliden-fauna von Peru. Stuttgarter Beiträg zur

Naturkunde 67: 1-14.

Recebido em 14.XII.2001; aceito em 25.VI.2002. 